\title{
How Systemic Sclerosis Affects Healthcare Use and Complication Rates after Total Hip Arthroplasty
}

\author{
Jasvinder A. Singh (1D) and John D. Cleveland
}

\begin{abstract}
Objective. To assess whether outcomes after primary total hip arthroplasty (THA) differ in systemic sclerosis (SSc).

Methods. We used the 1998-2014 US National Inpatient Sample. THA and SSc were identified using procedure and diagnostic codes, respectively. Multivariable-adjusted logistic regression analyses assessed the association of SSc with in-hospital complications (implant infection, revision, transfusion, mortality) post-THA and associated healthcare use (hospital charges, hospital stay, discharge to non-home setting), adjusting for age, sex, race, Deyo-Charlson comorbidity index, primary diagnosis for THA, household income, and insurance payer.

Results. Of the 4,116,485 primary THA performed in the United States in 1998-2014, SSc patients made up $0.06 \%(\mathrm{n}=2672)$. In multivariable-adjusted analyses, compared to people without SSc, people with SSc had higher adjusted OR (95\% CI) of the following post-primary THA: (1) non-home discharge, 1.25 (95\% CI 1.03-1.50); (2) hospital stay > 3 days, 1.61 (95\% CI 1.35-1.92); (3) transfusion, 1.54 (95\% CI 1.28-1.84); and (4) in-hospital revision, 9.53 (95\% CI 6.75-13.46). Differences in in-hospital mortality had a nonsignificant trend [2.19 (95\% CI 0.99-4.86)]. There were no differences in total hospital charges or implant infection rates.

Conclusion. SSc was associated with a higher rate of in-hospital complications and healthcare use after primary THA. Future studies should examine whether pre- or postoperative interventions can reduce the risk of post-THA complications in people with SSc. (First Release April 1 2020; J Rheumatol 2020;47:1218-23; doi:10.3899/jrheum.190783)
\end{abstract}

Key Indexing Terms:

SYSTEMIC SCLEROSIS

HIP

\section{SCLERODERMA OUTCOMES}

\section{ARTHROPLASTY EPIDEMIOLOGY}

Systemic sclerosis ( $\mathrm{SSc}$ ), also called scleroderma, is a multisystem, chronic autoimmune disease characterized by skin thickening, Raynaud phenomenon, and cardiopulmonary and gastrointestinal (GI) system involvement. Despite the associated high morbidity and mortality burden of $\mathrm{SSc}^{1}$, survival rates have improved over time ${ }^{2}$. Improved survival puts SSc patients at risk of age-related diseases, such as endstage hip arthritis, similar to the general population.

Total hip arthroplasty (THA) is a common surgery for

From the Birmingham Veterans Affairs (VA) Medical Center, Birmingham, Alabama; Department of Medicine at the School of Medicine, and Division of Epidemiology at the School of Public Health, University of Alabama at Birmingham, Birmingham, Alabama, USA.

Supported by research funds from the Division of Rheumatology at the University of Alabama at Birmingham and the resources and facilities at the Birmingham VA Medical Center, Birmingham, Alabama, USA. The funding body did not play any role in the design of the study or in the collection, analysis, and interpretation of data; in the writing of the manuscript; or in the decision to submit the manuscript for publication.

J.A. Singh, MBBS, MPH, Birmingham VA Medical Center, and Department of Medicine at the School of Medicine and Division of Epidemiology at the School of Public Health, University of Alabama at Birmingham; J.D. Cleveland, MS, Department of Medicine at the School of Medicine, University of Alabama at Birmingham.

Address correspondence to J.A. Singh, University of Alabama at Birmingham, Faculty Office Tower 805B, 510 20th St. S, Birmingham, Alabama 35294-0022, USA.E-mail: Jasvinder.md@gmail.com

Accepted for publication September 30, 2019. endstage arthritis of the hip that reduces pain and improves function and quality of life (QOL), and its use is rapidly increasing ${ }^{3}$. The most common underlying causes for THA are osteoarthritis (OA), avascular bone necrosis (AVN), and rheumatoid arthritis (RA). Many previous studies have examined patient and surgeon characteristics, the underlying diagnosis (OA vs RA vs AVN vs fracture), and medical comorbidity as potential predictors of THA outcomes ${ }^{4}$. To our knowledge, THA outcomes have not been studied in SSc. Our study objective was to examine the independent association of SSc with THA outcomes, (i.e., healthcare use and in-hospital complication rates) in a national US cohort.

\section{MATERIALS AND METHODS}

Data source and study cohort selection. Our study cohort included all hospitalizations for primary THA in the US National Inpatient Sample (NIS) 1998-2014. NIS is the largest publicly available, deidentified all-payer inpatient healthcare database in the United States. NIS consists of a $20 \%$ stratified sample of discharge records from all participating community hospitals from all participating states ${ }^{5}$. It is extensively used for epidemiological studies of hospitalization, mortality, and costs, because it represents all hospitalizations in the United States.

We identified primary THA based on the presence of International Classification of Disease, 9th revision, Clinical Modification (ICD-9-CM) procedure code of 81.51 , listed as the primary procedure for hospitalization. This validated approach has positive predictive values of $98-99 \% \%^{6,7}$ The University of Alabama at Birmingham's Institutional Review Board

Personal non-commercial use only. The Journal of Rheumatology Copyright $@$ 2020 . All rights reserved. 
approved this study (UAB; X120207004) and waived the need for informed consent for this database study. All investigations were conducted in conformity with ethical principles of research.

Exposure, outcomes, and covariates. The exposure of interest was the presence of SSc at index hospitalization, based on the presence of an ICD-9 code of 710.1 in a non-primary position during the index hospitalization, a validated approach with sensitivity of $80 \%$ and specificity of $95 \%$. We examined the following outcomes post-primary THA: (1) healthcare use: total hospital charges (above the median for each calendar year), the length of hospital stay (above the median of 3 days), the discharge disposition to home versus non-home settings (rehabilitation or inpatient facility); (2) in-hospital complications, implant infection, transfusion, or revision, (identified by respective ICD-9-CM codes), and in-hospital mortality.

We adjusted our main models for covariates/confounders, including age, sex, race, the underlying primary diagnosis for THA, household income, the insurance payer, and Deyo-Charlson comorbidity index ${ }^{9}$, a validated measure of medical comorbidity that includes 17 comorbidities with a score ranging 0-25 (higher score indicating greater comorbidity load).

Statistical analyses. We followed the survey analysis procedures that take into account the weights, clusters, and strata as defined in the NIS, including the modified weights with the change in sampling in 2012. Summary statistics were compared using chi-square or Student t test, as appropriate. We performed multivariable-adjusted logistic regression analyses for each study outcome, adjusting for all covariates listed in the section above. OR and $95 \%$ CI were calculated.

Sensitivity analyses additionally adjusted the main analyses for hospital characteristics including hospital location/teaching status, bed size, and region, previously associated with THA outcomes ${ }^{6}$. We used SAS 9.3 (SAS Institute Inc.) for all analyses. We considered a p value $<0.05$ to be statistically significant.

\section{RESULTS}

Of the 4,116,485 primary THA performed from 1998 to 2014 in the United States, $2672(0.06 \%)$ were done on patients with SSc (Table 1). Compared to people without $\mathrm{SSc}$, people with SSc were younger and more likely to be female or have higher Deyo-Charlson comorbidity index score or an underlying diagnosis of avascular bone necrosis (Table 1A). Unadjusted rates of in-hospital transfusion, revision, or death were higher in people with SSc (Table 1B).

In multivariable-adjusted analyses, compared to people without SSc, people with SSc had higher odds of non-home discharge, hospital stay $>3$ days (Table 2), in-hospital transfusion, or in-hospital revision post-primary THA, with OR of 1.25 (95\% CI 1.03-1.50), 1.61 (95\% CI 1.35-1.92), 1.54 (95\% CI 1.28-1.84), and 9.53 (95\% CI 6.75-13.46), respectively. Other variables significantly associated with outcomes are shown in Table 2. No differences were seen in total hospital charges or implant infection rates; the mortality rate was borderline significant and higher in SSc (OR 2.19, 95\% CI 0.99-4.86; Table 2). Sensitivity analyses confirmed the main findings with minimal attenuation of OR (Appendix 1).

\section{DISCUSSION}

In a study using a US national sample, SSc was associated with higher odds of non-home discharge, and a longer hospital stay after primary THA. Patients with SSc were also more likely to have in-hospital transfusion or revision surgery, and had a trend toward higher in-hospital mortality after primary THA. Odds were higher, ranging from 1.5 - to 10 -fold, which are arguably clinically meaningful differences. We noted no association of SSc with total hospital charges or implant infection rates.

SSc-associated interstitial lung disease (ILD), pulmonary hypertension (HTN), acute renal failure, aspiration, pericarditis/cardiomyopathy, and a higher infection risk may be responsible for a longer hospital stay in patients with $\mathrm{SSc}^{1,10}$. Higher likelihood of non-home discharge in patients with SSc might be related to a more protracted rehabilitation due to associated skin disease and arthritis ${ }^{11}$ and/or a poorer social network ${ }^{12}$. Physical rehabilitation reduces disability and improves function in people with $\mathrm{SSc}^{13,14}$. A tailored, multidisciplinary rehabilitation program is successful in $\mathrm{SSc}^{15}$. Whether combining an SSc-specific rehabilitation program with THA rehabilitation can improve QOL in the post-THA period and reduce healthcare use remains to be seen. Pre-habilitation with an SSc-focused program is a potential intervention that merits testing in patients with $\mathrm{SSc}$ who are undergoing elective primary THA.

The in-hospital transfusion rate in SSc was higher than among those without SSc. One-third of all patients with SSc have anemia ${ }^{16}$. Anemia of chronic disease and/ or anemia related to iron deficiency from low oral intake, heavy menses, or GI blood loss secondary to gastric antral vascular ectasia or intestinal mucosal telangiectasias are common in SSc; microangiopathic hemolytic anemia may rarely contribute ${ }^{17}$. Postoperative risk of GI bleeding may be elevated in SSc after THA.

Patients with SSc had higher odds of in-hospital revision surgery. Unadjusted absolute revision rates were low, $0.4 \%$ in non-SSc versus $1.8 \%$ in SSc, and adjusted odds were 10 -fold higher in SSc. Instability, dislocation, and periprosthetic fractures are common causes of early THA failure ${ }^{18}$ leading to revision. The musculoskeletal morbidity in SSc may increase the risk of these complications post-THA ${ }^{19}$. $\mathrm{SSc}$-associated calcinosis and possibly higher general infection risk ${ }^{1,10}$ may also contribute. Interestingly, implant infection (another cause of revision) risk did not differ between patients with SSc and those without.

Patients with SSc had a nonsignificant trend toward higher mortality post-THA. Diabetes, anxiety, and depression increased in-hospital mortality in hospitalized patients with $\mathrm{SSc}^{20}$. Other examples of SSc-associated end-organ involvement that can also contribute to higher mortality include scleroderma renal crisis, ILD, pulmonary HTN, pericarditis/ cardiomyopathy, and heart failure. The increased risk of infections likely contributes as well ${ }^{1,10}$. Several complications can be avoided with closer pre-, intra-, and post-THA monitoring, by including the appropriate specialist/s in the perioperative period.

In our cohort of post-THA patients with SSc, the hospital charges were higher (US\$38,964) and mortality $(0.7 \%)$ lower

Personal non-commercial use only. The Journal of Rheumatology Copyright $@$ 2020 . All rights reserved. 
Table 1A. Demographic and other cohort characteristics.

\begin{tabular}{|c|c|c|c|}
\hline National Estimates* & Entire Cohort, $\mathrm{n}=4,116,485^{*}$ & No SSc, $n=4,113,813^{*}$ & $\mathrm{SSc}, \mathrm{n}=2672 *$ \\
\hline Age, yrs, mean (SE); median & $65.2(0.04) ; 65.9$ & $65.5(0.04) ; 66.0$ & $63.6(0.54) ; 64.5$ \\
\hline \multicolumn{4}{|l|}{ Age category, yrs } \\
\hline$<50$ & $449,642(10.9)$ & $449,321(10.9)$ & $321(12.0)$ \\
\hline $50-64$ & $1,364,821(33.2)$ & $1,363,891(33.2)$ & $930(34.8)$ \\
\hline $65-79$ & $1,732,014(42.1)$ & $1,730,790(42.1)$ & $1224(45.8)$ \\
\hline$\geq 80$ & $566,521(13.8)$ & $566,324(13.8)$ & $197(7.4)$ \\
\hline \multicolumn{4}{|l|}{ Sex } \\
\hline Female & $2,330,188(56.6)$ & $2,327,919(56.6)$ & $2269(84.9)$ \\
\hline Male & $1,776,722(43.2)$ & $1,776,320(43.2)$ & $402(15.1)$ \\
\hline \multicolumn{4}{|l|}{ Race } \\
\hline White & $2,882,041(70.0)$ & $2,880,179(70.0)$ & $1862(69.7)$ \\
\hline Black & $225,772(5.5)$ & $225,583(5.5)$ & $189(7.1)$ \\
\hline Hispanic & $104,385(2.5)$ & $104,255(2.5)$ & $130(4.9)$ \\
\hline Other/missing & $904,234(22.0)$ & $903,743(22.0)$ & $491(18.4)$ \\
\hline \multicolumn{4}{|l|}{ Deyo-Charlson Score } \\
\hline 0 & $2,193,575(53.3)$ & $2,193,575(53.3)$ & $0(0.0)$ \\
\hline 1 & $926,287(22.5)$ & $924,825(22.5)$ & $1462(54.7)$ \\
\hline$\geq 2$ & $996,624(24.2)$ & $995,414(24.2)$ & $1210(45.3)$ \\
\hline \multicolumn{4}{|l|}{ Primary diagnosis } \\
\hline RA & $29,174(0.7)$ & $29,099(0.7)$ & $75(2.8)$ \\
\hline Avascular bone necrosis & $285,622(6.9)$ & $285,200(6.9)$ & $422(15.8)$ \\
\hline Osteoarthritis & $3,447,224(83.7)$ & $3,445,373(83.8)$ & $1851(69.3)$ \\
\hline Other & $354,307(8.6)$ & $353,984(8.6)$ & $323(12.1)$ \\
\hline Fracture & $117(0.0)$ & $117(0.0)$ & $0(0.0)$ \\
\hline \multicolumn{4}{|l|}{ Insurance } \\
\hline Medicaid & $138,809(3.4)$ & $138,727(3.4)$ & $82(3.1)$ \\
\hline Medicare & $2,234,674(54.3)$ & $2,233,071(54.3)$ & $1603(60.0)$ \\
\hline Other & $102,276(2.5)$ & $102,246(2.5)$ & $30(1.1)$ \\
\hline Private & $1,600,830(38.9)$ & $1,599,902(38.9)$ & $928(34.7)$ \\
\hline Self & $32,307(0.8)$ & $32,293(0.8)$ & $14(0.5)$ \\
\hline \multicolumn{4}{|l|}{ Income category } \\
\hline $0-25$ th percentile & $653,243(15.9)$ & $652,828(15.9)$ & $415(15.5)$ \\
\hline 25th-50th percentile & $1,009,677(24.5)$ & $1,009,042(24.5)$ & $635(23.8)$ \\
\hline 50th-75th percentile & $1,086,953(26.4)$ & $1,086,239(26.4)$ & 714 (26.7) \\
\hline 75th-100th percentile & $1,285,855(31.2)$ & $1,284,984(31.2)$ & $871(32.6)$ \\
\hline \multicolumn{4}{|l|}{ Hospital location/teaching } \\
\hline Rural & $444,188(10.8)$ & 444,031 (10.8) & $157(5.9)$ \\
\hline Urban & $1,722,390(41.8)$ & $1,721,393(41.8)$ & 997 (37.3) \\
\hline Urban teaching & 1,939,988 (47.1) & $1,938,471(47.1)$ & $1517(56.8)$ \\
\hline \multicolumn{4}{|l|}{ Hospital bed size } \\
\hline Small & $685,209(16.6)$ & $684,783(16.6)$ & $426(15.9)$ \\
\hline Medium & $1,037,562(25.2)$ & $1,036,856(25.2)$ & $706(26.4)$ \\
\hline Large & 2,383,797 (57.9) & $2,382,257(57.9)$ & $1540(57.6)$ \\
\hline \multicolumn{4}{|l|}{ Hospital region } \\
\hline Northeast & $818,699(19.9)$ & 818,058 (19.9) & $641(24.0)$ \\
\hline Midwest & $1,089,883(26.5)$ & $1,089,259(26.5)$ & $624(23.4)$ \\
\hline South & $1,358,856(33.0)$ & $1,357,985(33.0)$ & $871(32.6)$ \\
\hline West & 849,045 (20.6) & $848,511(20.6)$ & $534(20.0)$ \\
\hline
\end{tabular}

compared to all SSc hospitalizations in the US NIS data, at $\$ 8885$ and 5\%, respectively ${ }^{10}$. This should be expected, because the THA subsample in our study represents patients with SSc who are fit enough to undergo major surgery (elective in $>75 \%$ cases), and in addition both perioperative evaluation and preoperative comorbidity optimization are performed (to some extent) in these patients to reduce postoperative complications.

Our study strengths include the use of a national US hospitalization sample, the adjustment of models for potential confounders, and the robustness of effect estimates in sensitivity analyses.

Our study has several limitations. The use of ICD-9-CM codes to identify people with SSc and with THA puts our study at the risk of misclassification bias. However, ICD-9-CM codes for $\mathrm{SSc}^{8}$ and THA ${ }^{6,7}$ were valid in previous studies, indicating that this bias may be limited. We recognize that in-hospital complications constitute a small 
Table 1B. In-hospital complications*** and healthcare use.

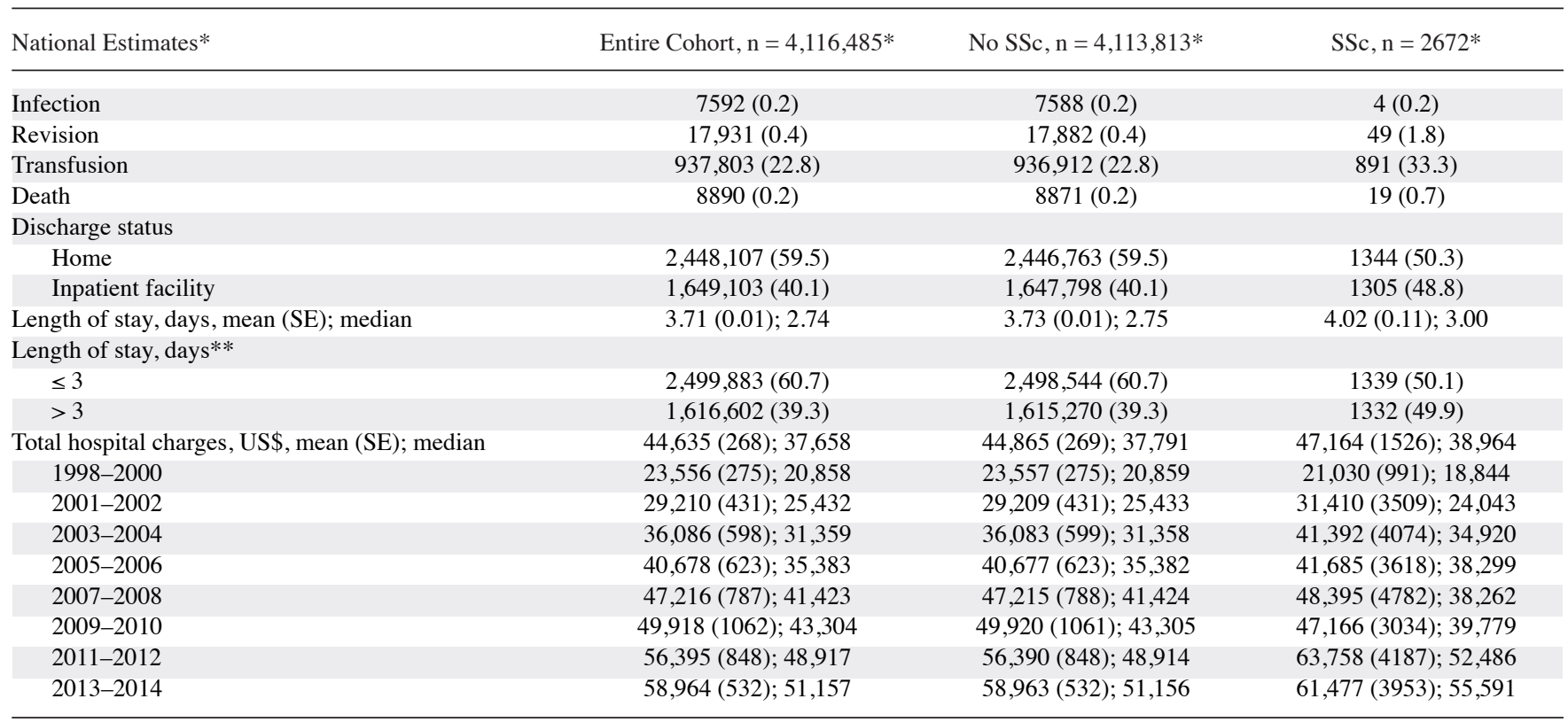

Values are n (\%) unless otherwise specified. * US national estimates were based on the National Inpatient Sample, a 20\% sample of all US hospitalizations; details are available at: www.hcup-us.ahrq.gov/nisoverview.jsp. The actual numbers were entire cohort, $\mathrm{n}=855,634 ;$ no systemic sclerosis, $\mathrm{n}=855,079$; and systemic sclerosis, $\mathrm{n}=555$. ** Length of hospital stay dichotomized at 3 days, by rounding off the median of 2.7 days to 3 days. *** Infection was identified by the presence of ICD-9-CM code 711.xx, 730.xx, 996.66, or 996.67. Transfusion was identified with the ICD-9-CM code of 99.0x. Revision was identified with ICD-9-CM codes of $81.53,00.70,00.72,00.73,84.56,84.57$ or 80.05 . SSc: systemic sclerosis; SE: standard error; ICD-9-CM; International Classification of Diseases, 9th revision, Clinical Modification; RA: rheumatoid arthritis.

proportion of all post-THA complications. Lack of data on SSc clinical features at the time of hospitalization including SSc subtype and duration, skin scores, ILD, pulmonary HTN, cardiac function, and calcinosis limited our ability to examine the role of these disease severity factors on outcomes. Future studies that include longitudinal outcome analyses at a patient level are needed to better understand whether 30- and 90-day complications post-THA are higher in people with SSc.

We conducted a national US cohort study of primary THA hospitalizations among people with versus without SSc. We found that SSc was associated with a higher risk of in-hospital transfusion and revision surgery, a longer hospital stay, and higher discharge rates to a non-home setting. A nonsignificant trend toward higher in-hospital mortality was also noted in people with SSc. Future studies should assess the reasons for higher complication rates and healthcare use in people with SSc undergoing primary THA and design appropriate interventions.

\section{REFERENCES}

1. Chung L, Domsic RT, Lingala B, Alkassab F, Bolster M, Csuka $\mathrm{ME}$, et al. Survival and predictors of mortality in systemic sclerosisassociated pulmonary arterial hypertension: outcomes from the pulmonary hypertension assessment and recognition of outcomes in scleroderma registry. Arthritis Care Res 2014;66:489-95.

2. Kennedy N, Walker J, Hakendorf P, Roberts-Thomson P. Improving life expectancy of patients with scleroderma: results from the South Australian scleroderma register. Intern Med J 2018;48:951-6.
3. Cram P, Lu X, Kaboli PJ, Vaughan-Sarrazin MS, Cai X, Wolf $\mathrm{BR}$, et al. Clinical characteristics and outcomes of medicare patients undergoing total hip arthroplasty, 1991-2008. JAMA 2011;305:1560-7.

4. Hofstede SN, Gademan MG, Vliet Vlieland TP, Nelissen RG, Marang-van de Mheen PJ. Preoperative predictors for outcomes after total hip replacement in patients with osteoarthritis: a systematic review. BMC Musculoskelet Disord 2016;17:212.

5. Healthcare Cost and Utilization Project (HCUP). Overview of the National (Nationwide) Inpatient Sample (NIS). (Internet. Accessed February 25, 2020.) Available from: www.hcup-us.ahrq.gov/ nisoverview.jsp

6. Katz JN, Losina E, Barrett J, Phillips CB, Mahomed NN, Lew RA, et al. Association between hospital and surgeon procedure volume and outcomes of total hip replacement in the United States Medicare population. J Bone Joint Surg Am 2001;83:1622-9.

7. Singh JA, Ayub S. Accuracy of VA databases for diagnoses of knee replacement and hip replacement. Osteoarthritis Cartilage 2010;18:1639-42.

8. Bernatsky S, Linehan T, Hanly JG. The accuracy of administrative data diagnoses of systemic autoimmune rheumatic diseases. J Rheumatol 2011;38:1612-6.

9. Deyo RA, Cherkin DC, Ciol MA. Adapting a clinical comorbidity index for use with ICD-9-CM administrative databases. J Clin Epidemiol 1992;45:613-9.

10. Ram Poudel D, George M, Dhital R, Karmacharya P, Sandorfi N, Derk CT. Mortality, length of stay and cost of hospitalization among patients with systemic sclerosis: results from the National Inpatient Sample. Rheumatology 2018;57:1611-22.

11. Casale R, Buonocore M, Matucci-Cerinic M. Systemic sclerosis (scleroderma): an integrated challenge in rehabilitation. Arch Phys Med Rehabil 1997;78:767-73.

12. Cinar FI, Unver V, Yilmaz S, Cinar M, Yilmaz F, Simsek

Personal non-commercial use only. The Journal of Rheumatology Copyright @ 2020 . All rights reserved. 
Table 2. Multivariable-adjusted association of SSc and other clinical variables with healthcare use outcomes and in-hospital implant infection, transfusion, revision, and mortality post-primary $\mathrm{THA}^{*}$.

\begin{tabular}{lcccccc}
\hline Variables & Total Hospital & Discharge to & Length of & In-hospital & In-hospital & In-hospital \\
& Charges above & Non-home & Hospital Stay & Implant & Transfusion & Revision \\
& the Median** & Settings & $>3$ Days & Infection & Mortality
\end{tabular}

\begin{tabular}{|c|c|c|c|c|c|c|c|}
\hline SSc & $0.90(0.76-1.07)$ & $1.25(1.03-1.50)$ & $1.61(1.35-1.92)$ & $0.93(0.22-3.99)$ & $1.54(1.28-1.84)$ & $9.53(6.75-13.46)$ & $2.19(0.99-4.86)$ \\
\hline \multicolumn{8}{|l|}{ Age category, yrs } \\
\hline$<50$ & Ref & Ref & Ref & Ref & Ref & Ref & Ref \\
\hline $50-64$ & $0.86(0.82-0.90)$ & $1.75(1.71-1.78)$ & $1.09(1.08-1.11)$ & $0.97(0.82-1.16)$ & $1.11(1.09-1.13)$ & $0.96(0.84-1.11)$ & $0.77(0.71-0.83)$ \\
\hline $65-79$ & $0.88(0.84-0.93)$ & $3.36(3.28-3.44)$ & $1.37(1.35-1.40)$ & $0.93(0.74-1.15)$ & $1.30(1.26-1.33)$ & $0.90(0.76-1.07)$ & $0.90(0.81-1.01)$ \\
\hline$\geq 80$ & $1.01(0.95-1.07)$ & $10.75(10.46-11.04)$ & $1.95(1.90-1.99)$ & $0.94(0.74-1.19)$ & $1.85(1.80-1.90)$ & $0.92(0.76-1.11)$ & $2.50(2.24-2.80)$ \\
\hline \multicolumn{8}{|c|}{ 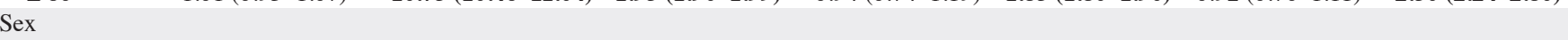 } \\
\hline Male & Ref & Ref & Ref & Ref & Ref & Ref & Ref \\
\hline Female & $0.97(0.95-1.00)$ & $1.73(1.71-1.75)$ & $1.20(1.19-1.21)$ & $0.95(0.87-1.04)$ & $1.68(1.66-1.70)$ & $1.01(0.93-1.09)$ & $0.91(0.86-0.97)$ \\
\hline \multicolumn{8}{|l|}{ Race/ethnicity } \\
\hline White & Ref & Ref & Ref & Ref & Ref & Ref & Ref \\
\hline Black & $0.61(0.58-0.64)$ & $1.67(1.63-1.70)$ & $1.38(1.35-1.41)$ & $1.16(0.95-1.41)$ & $1.39(1.36-1.42)$ & $1.24(1.05-1.47)$ & $1.07(0.92-1.24)$ \\
\hline Hispanic & $0.41(0.39-0.43)$ & $1.40(1.35-1.44)$ & $1.33(1.29-1.37)$ & $1.24(0.96-1.61)$ & $1.33(1.29-1.37)$ & $1.04(0.83-1.30)$ & $0.86(0.73-1.01)$ \\
\hline Other/missing & $2.50(2.40-2.61)$ & $1.06(1.05-1.07)$ & $1.39(1.37-1.40)$ & $1.04(0.93-1.16)$ & $0.93(0.92-0.94)$ & $1.10(1.00-1.22)$ & $1.00(0.93-1.07)$ \\
\hline \multicolumn{8}{|c|}{ Deyo-Charlson score } \\
\hline 0 & Ref & Ref & Ref & Ref & Ref & Ref & Ref \\
\hline 1 & $0.96(0.93-0.99)$ & $1.20(1.19-1.22)$ & $0.95(0.94-0.96)$ & $1.02(0.91-1.14)$ & $0.96(0.95-0.97)$ & $0.93(0.84-1.03)$ & $1.09(1.02-1.17)$ \\
\hline$\geq 2$ & $0.75(0.73-0.78)$ & $0.95(0.94-0.97)$ & $0.58(0.58-0.59)$ & $1.04(0.94-1.16)$ & $0.78(0.77-0.79)$ & $0.92(0.83-1.01)$ & $1.46(1.37-1.55)$ \\
\hline \multicolumn{8}{|c|}{ Primary diagnosis } \\
\hline RA & Ref & Ref & Ref & Ref & Ref & Ref & Ref \\
\hline \multicolumn{8}{|l|}{ Avascular bone } \\
\hline necrosis & $1.03(0.89-1.21)$ & $0.89(0.84-0.95)$ & $0.84(0.79-0.89)$ & $1.53(0.65-3.60)$ & $0.82(0.78-0.88)$ & $1.25(0.77-2.02)$ & $0.89(0.59-1.34)$ \\
\hline Osteoarthritis & $0.93(0.80-1.08)$ & $0.66(0.62-0.70)$ & $0.51(0.48-0.54)$ & $0.85(0.37-1.96)$ & $0.66(0.62-0.69)$ & $0.84(0.53-1.32)$ & $0.77(0.53-1.13)$ \\
\hline Other & $0.98(0.84-1.14)$ & $1.65(1.55-1.75)$ & $2.30(2.18-2.43)$ & $3.70(1.59-8.59)$ & $1.03(0.97-1.09)$ & $4.83(3.04-7.66)$ & $7.22(4.95-10.53)$ \\
\hline Fracture & $0.66(0.09-5.03)$ & $11.50(3.39-39.02)$ & $11.84(2.55-54.85)$ & Not estimable & $1.16(0.47-2.82)$ & Not estimable & Not estimable \\
\hline \multicolumn{8}{|c|}{ Insurance payer } \\
\hline Private & Ref & Ref & Ref & Ref & Ref & Ref & Ref \\
\hline Medicare & $0.99(0.96-1.03)$ & $2.06(2.02-2.09)$ & $1.34(1.32-1.36)$ & $1.01(0.86-1.19)$ & $1.18(1.16-1.20)$ & $1.04(0.91-1.18)$ & $1.14(1.04-1.26)$ \\
\hline Medicaid & $1.38(1.27-1.51)$ & $1.72(1.67-1.77)$ & $1.70(1.65-1.74)$ & $1.76(1.43-2.17)$ & $1.17(1.14-1.21)$ & $1.53(1.28-1.82)$ & $0.89(0.75-1.05)$ \\
\hline Other & $1.92(1.72-2.14)$ & $1.10(1.06-1.14)$ & $1.32(1.28-1.37)$ & $1.38(1.06-1.80)$ & $1.00(0.97-1.04)$ & $1.04(0.82-1.32)$ & $0.83(0.69-1.01)$ \\
\hline Self & $1.24(1.05-1.46)$ & $0.56(0.52-0.61)$ & $1.50(1.43-1.58)$ & $1.30(0.84-2.03)$ & $1.11(1.04-1.18)$ & $1.41(1.01-1.95)$ & $0.90(0.64-1.25)$ \\
\hline \multicolumn{8}{|c|}{ Income category, percentile } \\
\hline $0-25$ th & $2.48(2.38-2.59)$ & $0.81(0.80-0.82)$ & $0.86(0.85-0.87)$ & $0.96(0.84-1.10)$ & $0.82(0.81-0.84)$ & $0.98(0.87-1.11)$ & $0.98(0.90-1.06)$ \\
\hline 25th-50th & $2.19(2.12-2.27)$ & $0.83(0.82-0.84)$ & $0.94(0.93-0.96)$ & $0.99(0.88-1.11)$ & $0.79(0.78-0.80)$ & $1.04(0.94-1.16)$ & $0.99(0.93-1.07)$ \\
\hline 50th-75th & $1.55(1.50-1.60)$ & $0.86(0.85-0.87)$ & $0.91(0.90-0.92)$ & $0.99(0.88-1.12)$ & $0.79(0.78-0.81)$ & $0.99(0.89-1.10)$ & $0.96(0.89-1.03)$ \\
\hline 75th-100th & Ref & Ref & Ref & Ref & Ref & Ref & Ref \\
\hline
\end{tabular}

Data are OR $(95 \% \mathrm{CI})$. Values in bold face indicate significant OR. An OR $>1$ indicates that SSc patients had higher odds of that outcome, including in-hospital complication (e.g., mortality) and healthcare use (charges, stay, discharge disposition). A 95\% CI that did not include unity (1.0) indicates that the association is statistically significant with a p value $<0.05$. * Model included the following variables: age, sex, race, Deyo-Charlson comorbidity index, the underlying primary diagnosis for THA, household income, insurance payer, SSc diagnosis. ** Median hospital charges were as follows: 1998, $\$ 19,717 ; 1999$, $\$ 20,514$; $2000, \$ 22,333 ; 2001, \$ 24,189 ; 2002, \$ 26,729 ; 2003, \$ 29,858 ; 2004, \$ 32,607 ; 2005, \$ 34,615 ; 2006, \$ 36,164 ; 2007, \$ 39,675 ; 2008, \$ 43,064 ; 2009, \$ 41,602$; 2010 , $\$ 45,186 ; 2011, \$ 48,898 ; 2012, \$ 48,927 ; 2013, \$ 50,827 ; 2014$, $\$ 51,482$. SSc: systemic sclerosis; RA: rheumatoid arthritis; THA: total hip arthroplasty.

I, et al. Living with scleroderma: patients' perspectives, a phenomenological study. Rheumatol Int 2012;32:3573-9.

13. Antonioli CM, Bua G, Frige A, Prandini K, Radici S, Scarsi M, et al. An individualized rehabilitation program in patients with systemic sclerosis may improve quality of life and hand mobility. Clin Rheumatol 2009;28:159-65.

14. Maddali-Bongi S, Del Rosso A. Systemic sclerosis: rehabilitation as a tool to cope with disability. Clin Exp Rheumatol 2016;34 Suppl 100:162-9.

15. Maddali Bongi S, Del Rosso A, Galluccio F, Tai G, Sigismondi F, Passalacqua $\mathrm{M}$, et al. Efficacy of a tailored rehabilitation program for systemic sclerosis. Clin Exp Rheumatol 2009;3 Suppl 54:44-50.

16. Westerman MP, Martinez RC, Medsger TA Jr, Totten RS, Rodnan
GP. Anemia and scleroderma: frequency, causes, and marrow findings. Arch Intern Med 1968;122:39-42.

17. Frayha RA, Shulman LE, Stevens MB. Hematological abnormalities in scleroderma. A study of 180 cases. Acta Haematol 1980;64:25-30.

18. Melvin JS, Karthikeyan T, Cope R, Fehring TK. Early failures in total hip arthroplasty -- a changing paradigm. J Arthroplasty 2014;29:1285-8.

19. Pope JE. Musculoskeletal involvement in scleroderma. Rheum Dis Clin North Am 2003;29:391-408.

20. Amoda O, Ravat V, Datta S, Saroha B, Patel RS. Trends in demographics, hospitalization outcomes, comorbidities, and mortality risk among systemic sclerosis patients. Cureus 2018;10:e2628. 
APPENDIX 1. Sensitivity analyses* adjusting the main multivariable-adjusted models for hospital location/teaching status, region, and bed size, assessing the association of systemic sclerosis (SSc) with healthcare use and in-hospital complications.

\begin{tabular}{|c|c|c|c|c|c|c|c|}
\hline & $\begin{array}{l}\text { Total Hospital } \\
\text { Charges above } \\
\text { the Median }\end{array}$ & $\begin{array}{l}\text { Discharge to } \\
\text { Non-home } \\
\text { Settings }\end{array}$ & $\begin{array}{l}\text { Length of } \\
\text { Hospital Stay } \\
\text { > } 3 \text { Days }\end{array}$ & $\begin{array}{l}\text { In-hospital } \\
\text { Implant } \\
\text { Infection }\end{array}$ & $\begin{array}{l}\text { In-hospital } \\
\text { Transfusion }\end{array}$ & $\begin{array}{l}\text { In-hospital } \\
\text { Revision } \\
\text { Surgery }\end{array}$ & $\begin{array}{c}\text { In-hospital } \\
\text { Mortality }\end{array}$ \\
\hline $\mathrm{SSc}$ & $0.88(0.74-1.04)$ & $1.23(1.01-1.48)$ & $1.62(1.35-1.93)$ & $0.92(0.22-3.92)$ & $1.54(1.28-1.85)$ & $9.55(6.74-13.53)$ & $2.20(0.97-5.02)$ \\
\hline
\end{tabular}

Data are OR $(95 \% \mathrm{CI})$ * Model included age, sex, race, Deyo-Charlson comorbidity index, primary diagnosis, insurance, income, SSc (main model) plus hospital location/teaching status, region, and bed size. Data are OR (95\% CI). Values in bold face are statistically significant. 